\title{
0 medo da morte flexibiliza perdas e aproxima polos: consequências políticas da pandemia da COVID-19 no Brasil
}

Carlos Pereira ${ }^{1}$

Amanda Medeiros 1

Frederico Bertholini 2

1 Fundação Getulio Vargas / Escola Brasileira de Administração Pública e de Empresas, Rio de Janeiro / RJ - Brasil

2 Universidade de Brasília / Instituto de Ciência Política, Brasília / DF - Brasil

Desde sempre a humanidade se aflige com o fim da existência. Em algumas ocasiões, como a atual pandemia do novo coronavírus, percebemos sua presença mais de perto. Até que ponto o medo da morte pode alterar percepções e crenças dos indivíduos? É nesse contexto de incertezas e medos que decidimos investigar de que modo a sociedade brasileira vem avaliando seus governantes, sobretudo em relação à política de isolamento social. A pandemia da COVID-19 alterou os eixos da polarização política. De um lado, governadores, prefeitos e legisladores preocupados com os riscos de estrangulamento do sistema de saúde causado pela pandemia. De outro, o presidente Jair Bolsonaro, focado primordialmente nas consequências econômicas negativas da política de isolamento social. Por meio de uma pesquisa de opinião, identificamos que o "medo da morte" diminuiu a polarização ideológica existente no Brasil desde a eleição de Jair Bolsonaro à presidência da República. Ao contrário do que muitos esperavam, os eleitores que se auto-identificaram como de direita e centro-direita - supostamente, o núcleo de eleitores de Bolsonaro - rejeitaram seguir a recomendação e avaliam mal a performance de seu líder. Também mostramos que essa mudança de comportamento não foi influenciada pelos diferentes níveis de renda.

Palavras-chave: COVID-19; ideologia; identidade; polarização política; populismo.

\section{El miedo a la muerte relativiza las pérdidas y acerca los polos: consecuencias políticas de la pandemia de COVID-19 en Brasil}

La humanidad siempre se ha afligido por el fin de la existencia. En algunas ocasiones, como en la pandemia actual del nuevo coronavirus, esa aflicción se hace más presente. ¿Hasta qué punto puede el miedo a la muerte alterar las percepciones y creencias de los individuos? Es en este contexto de incertidumbres y temores que decidimos investigar cómo la sociedad brasileña ha evaluado a sus líderes, especialmente con relación a la política de aislamiento social. La pandemia de COVID-19 cambió los ejes de polarización política. Por un lado, gobernadores, alcaldes y legisladores preocupados por los riesgos de estrangular el sistema de salud a causa de la pandemia. Por otro, el presidente Jair Bolsonaro centrado principalmente en las consecuencias económicas negativas de la política de aislamiento social. A través de una encuesta de opinión, identificamos que el "miedo a la muerte" disminuyó la polarización ideológica que ha existido en Brasil desde la elección de Jair Bolsonaro a la presidencia de la República. $\mathrm{Al}$ contrario de lo que muchos esperaban, los electores que se identificaron como de derecha y centroderecha, supuestamente los principales votantes de Bolsonaro, rechazaron cumplir con la recomendación y juzgaron mal el desempeño de su líder. También mostramos que este cambio en el comportamiento no fue influenciado por diferentes niveles de ingresos.

Palabras clave: COVID-19; ideología; identidad; polarización política; populismo.

Gostaríamos de agradecer ao jornal Estado de São Paulo pela colaboração e divulgação da pesquisa de campo junto aos seus leitores. Versões preliminares desse artigo foram apresentadas em webinars (https://www.youtube.com/watch?v=LZMTFyvUZ7A\&feature=youtu. be\&fbclid=IwAR2hid1ja80ZR588nuYClwdrZbcNDbCtTjxUoUXUcQ0C4mHX78qg9RiMEEE) com a participação de Sérgio Abranches, Mônica De Bole, Marcus Melo, Pedro Doria, Maria Hermínia Tavares de Almeida e Daniel Bramatti. Somos gratos aos comentários oferecidos pelos participantes. Também agradecemos as sugestões oferecidas por Rafael Goldszmidt e Eduardo Andrade. 


\section{Fear of death and polarization: political consequences of the COVID-19 pandemic}

Humanity has always been tormented with the end of existence. On some occasions, such as the current COVID-19 pandemic, this affliction is pronounced. To what extent can fear of death alter individuals' political perceptions and beliefs? It is in this context of uncertainties and fears that we investigate how Brazilian society has been evaluating its leaders, especially concerning the policy of social distancing. The COVID-19 pandemic changed the axes of political polarization. On the one hand, governors, mayors, and legislators are concerned about the risks of a collapse of the health system. On the other, President Jair Bolsonaro focused primarily on the negative economic consequences of the pandemic. Through an opinion poll, we identified that "fear of death" diminished the ideological polarization that has existed in Brazil since Jair Bolsonaro's election. Contrary to what many expected, voters who identified themselves as right-wing and center-right - supposedly, the core of Bolsonaro's voters - refused to follow the president's recommendation of relaxing social distancing policies and considered his performance inappropriate during the pandemic. We also show that different income levels did not influence this change in behavior.

Keywords: COVID-19; ideology; identity; political polarization; populism.

"Quem é você?

Eu sou a morte.

Você veio me buscar?

Eu tenho acompanhado você há muito tempo...

Eu sei.

Você está preparado?

Meu corpo está, mas eu não estou. Espere um instante...

Todos vocês dizem isso, mas não há trégua."

(O Sétimo Selo, Ingmar Bergman, 1956)

\section{INTRODUÇÃO}

O epílogo acima é o diálogo inicial entre a Morte e Antonius Block, cavaleiro que volta das Cruzadas, na Idade Média, e encontra sua terra natal completamente arrasada pela peste negra. O Sétimo Selo, obra-prima de Ingmar Bergman, tem por tema central a questão do medo da morte. Quando o cavaleiro se depara com a Morte, propõe-lhe uma negociação: uma disputa de xadrez. Enquanto jogam, o homem ganha tempo, pois sabe que não seria possível vencê-la, já que a Morte é inevitável, motivo pelo qual é impossível fugir de seu destino. Assim, a melhor saída seria adiá-la o máximo possível.

A pandemia do novo coronavírus foi um choque exógeno de grande magnitude, equivalente ao deslocamento de placas tectônicas. Atores e líderes políticos reagiram de forma extremada não apenas no Brasil, mas também em vários países do mundo.

Por um lado, os mais preocupados com a rapidez do contágio, a gravidade da doença e o risco de morte têm manifestado preferência por seguir as recomendações da Organização Mundial da Saúde (OMS), que prega o distanciamento social, mesmo diante das consequências negativas à economia. Quase todos os líderes de países que apresentaram casos da doença adotaram medidas de isolamento. Esse também tem sido o caso, por exemplo, de governadores, prefeitos e principais lideranças do legislativo no Brasil. 
Por outro lado, segmentos da população de alguns países e alguns de seus governos têm minimizado a virulência da pandemia e suas consequências à saúde, alegando preocupação com os efeitos econômicos adversos gerados pelas medidas de distanciamento social. ${ }^{1}$

O presidente brasileiro, Jair Bolsonaro, tem sido um dos principais defensores dessa estratégia de enfrentamento da pandemia. Além dele, os presidentes de Nicarágua, Daniel Ortega; Bielorrússia, Alexander Lukashenko; e Turcomenistão, Gurbanguly Berdimuhamedow, também se recusaram a decretar medidas de isolamento social. No início da pandemia, os presidentes de Estados Unidos, Donald Trump; México, López Obrador; Rússia, Vladimir Putin; e o primeiro-ministro italiano, Giuseppe Conte, também relutaram em apoiar o isolamento social, mas acabaram mudando a posição e passaram a defender que a população fique em casa.

Kingstone e Power (2017) argumentam a existência de um forte aumento da polarização política no Brasil desde de 2013, deflagrada com as grandes mobilizações de massa que varreram o país naquele ano. Para Hunter e Power (2019), esse aumento de polarização ficou visível tanto na grande massa quanto na elite política e econômica, tomando conta do país durante as eleições de 2018. Naquela ocasião, o número de eleitores que votaram num candidato de um dos polos se aproximou daquele relativo aos que expressaram forte antipatia pelo candidato oponente. Um dos polos foi ocupado pelo petismo, representando a política tradicional desgastada pelos sucessivos escândalos de corrupção. O outro polo era o do bolsonarismo, que a partir do antipetismo (Bello, 2019; Samuels \& Zucco, 2018), alimentou as expectativas de outro grupo social prometendo uma "nova política" baseada no antiestablishment.

Esse jogo de grupos polarizados estava em relativo "equilíbrio" até a pandemia do novo coronavírus, com cada grupo se nutrindo da oposição radicalizada de identidades e preferências políticas. Tais grupos não dialogavam entre si e tendiam a consumir informações que só reforçassem suas crenças anteriores. Ao mesmo tempo, rejeitavam qualquer informação que contrariasse os valores prévios, portanto não faziam atualizações que pudessem colocar em risco suas respectivas "zonas de conforto".

Seria possível imaginar alguma alteração no eixo da polarização política no Brasil, aproximando eleitores outrora situados em polos opostos? O medo da morte pode fazer emergirem novos eixos de polarização para além do embate entre esquerda e direita?

Para responder a essas perguntas, realizamos uma pesquisa de opinião que investigou a posição das pessoas em relação à política de isolamento social e à avaliação de desempenho do presidente e dos respectivos governadores na condução da política de contenção da COVID-19.

A hipótese principal da pesquisa é que a pandemia alterou os eixos da polarização política no país, aproximando os polos ideológicos antes extremados. Em outras palavras, a COVID-19 fez com que segmentos expressivos de eleitores alterassem sua percepção política diante do "medo da morte".

Os resultados confirmam que uma parcela significativa de eleitores auto-identificados como de centro-direita e direita apoia a política de isolamento social, na direção contrária à posição defendida pelo presidente Bolsonaro, alterando os termos da polarização no país e sugerindo sua diminuição. ${ }^{2}$

\footnotetext{
${ }^{1}$ Essa dicotomia, embora factualmente falsa, como apontam diversos especialistas (Martins, 2020; Pereira, 2020), permeia os discursos políticos de quem se opõe ao isolamento, por isso é apropriado defini-la. Isso se dá principalmente porque os discursos podem ter grande impacto no cumprimento ou não do isolamento, como mostram Ajzenman, Cavalcanti, e Da Mata (2020).

${ }^{2}$ Não se opor ao isolamento social, porém, não significa necessariamente renúncia de apoio ao presidente nem que esses eleitores estariam fazendo oposição a Bolsonaro em todas as suas políticas ou dimensões. Gostaríamos de agradecer a um dos revisores anônimos da RAP por nos chamar a atenção a esse aspecto.
} 
Tais eleitores também avaliam positivamente o desempenho dos governadores de seus respectivos estados e negativamente o do presidente durante a pandemia. Além disso, os setores de baixa renda, em tese mais vulneráveis, não apresentaram oposição sistemática à política de isolamento social quando comparados a pessoas pertencentes a outras faixas de renda.

A presente pesquisa traz contribuições empíricas e teóricas sobre o papel e os limites da ideologia e da afinidade identitária em moldar o comportamento político em ambientes polarizados. A ideologia, que é parte da identidade de uma pessoa (Huddy, 2001; Iborra, 2005; Teles, 2009), funciona como atalho cognitivo e protetivo para que aquelas que comungam de crenças e valores similares possam fazer escolhas (Huckfeldt et al., 1999). Argumentamos que, em situações-limite - por exemplo, quando a vida de pessoas e seus entes queridos está em risco -, os valores ideológicos e identitários podem deixar de ser a chave principal com base na qual as pessoas fazem suas escolhas. Ou seja, identidades ou ideologias se tornam maleáveis e, portanto, suscetíveis a ajustes e mudanças. Essas situações-limite podem criar problemas para quem pertence a determinado grupo, pois algumas vezes elas podem precisar escolher entre sua ideologia, que constitui sua identidade e as mantém ligadas ao grupo, e os riscos decorrentes dessa escolha na própria vida.

Na próxima seção, apresentamos nossa teoria baseada em um diálogo crítico com a literatura de populismo e identidade. Na terceira seção, descrevemos a metodologia e estatísticas descritivas. Na quarta e na quinta seções, apresentamos os principais resultados da pesquisa. Na sexta e última seção, concluímos o artigo destacando os principais resultados do estudo.

\section{POPULISMO IDENTITÁRIO}

A combinação de crise econômica de graves proporções e exposição cotidiana a sucessivos escândalos de corrupção gerou, em boa parte do eleitorado brasileiro, a percepção da política como algo sujo. Ao associar diretamente o estilo específico de presidencialismo de coalizão praticado pelos governos do Partido dos Trabalhadores (PT) à corrupção, Bolsonaro alimentou no eleitorado uma espécie de aversão à própria política, preenchendo assim um espaço aberto para o surgimento de populistas (Bakker, Rooduijn, \& Schumacher, 2016; Busby, Gubler, \& Hawkins, 2019; Hawkins, Kaltwasser, \& Andreadis, 2020).

O presidente eleito buscou preencher as expectativas de "limpeza" da política brasileira construindo uma plataforma inicialmente anti-PT, mas antipartido em sua essência, defendendo a ideia de que todas as siglas e seus membros seriam igualmente parte de uma elite corrupta. A viabilização eleitoral dessa crença se dá pelo enquadramento identitário que nega as instituições e enaltece a conexão direta entre o líder político e os eleitores. O pano de fundo dessa ideologia/identidade é a homogeneização e a mitificação das categorias "elites" e "povo", identificados como antagônicos (Bos et al., 2020; Mudde, 2004; Mudde \& Kaltwasser, 2012).

Uma vez eleito, Bolsonaro se recusou a construir uma coalizão e escolheu governar na condição de minoria. Para driblar essa fragilidade, buscou o estabelecimento de conexões diretas com os eleitores, adotando uma espécie de presidencialismo plebiscitário (Conaghan, 2008). No Congresso, atuou formando maiorias cíclicas a favor das preferências do Executivo, baseadas no constrangimento de legisladores via pressão da opinião pública. Ao adotar essa estratégia, que Kernell (2006) classifica como "going public", Bolsonaro governou numa espécie de campanha de polarização permanente. O tom conspiratório tem sido parte fundamental dessa cruzada do governo contra inimigos imprecisos que surgem a cada dia (Kovic \& Caspar, 2019). 
A negação sistemática dos instrumentos tradicionais de governo deixou poucas alternativas a Bolsonaro, inclusive durante a pandemia. A mobilização ininterrupta e radical de seus eleitores mais fiéis continuou a ser o modelo padrão de governança bolsonarista. O populismo plebiscitário implementado por ele se tornou, portanto, uma espécie de estratégia de reforço identitário e de proteção de seu núcleo central de eleitores.

Como mencionado, a ideologia faz parte da identidade do indivíduo de tal maneira que ele tende a se identificar com outras pessoas e grupos que dela compartilhem (Huddy, 2001). Na medida em que as pessoas tendem a ver como mais semelhante outras que compartilham da mesma ideologia (Mullen, Dovidio, Craig, \& Copper, 1992), divergir da orientação política do grupo a que pertence, em especial de seu principal líder, é muito doloroso. Por esse motivo, elas tendem a usar suas posições ideológicas e identitárias como lentes protetoras que reduzem as chances de os valores do grupo serem reavaliados.

A literatura sobre raciocínio motivado (motivated reasoning) sugere que os membros de um grupo interpretam informações de uma forma que beneficia o próprio bando (Bisgaard, 2015; Bolsen, Druckman, \& Cook, 2014; Leeper \& Slothuus, 2014), a fim de diminuir a dor gerada por atualizações informacionais que contrariam os valores nos quais se amparam. Assim, ao perceber que determinada posição é compartilhada pela comunidade a que pertencem, é esperado que seus membros desenvolvam estruturas narrativas próprias como mecanismo de defesa daquela posição (Bolsen et al., 2014).

Desse modo, os sentimentos de apego geram lealdade para os membros de cada grupo e proporcionam sensações de segurança e prestígio. Por outro lado, os indivíduos que não pertencem ao grupo desenvolvem hostilidade e aversão a valores e crenças de comunidades rivais, podendo inclusive enxergá-las como inimigos. Percebe-se uma importância intrínseca do compartilhamento de identidades e lealdades recíprocas entre indivíduos que pertencem a um grupo (in-group) e o distanciamento de indivíduos que estariam fora desse grupo (out-group), evocando vieses valorativos a favor de seu próprio bando e contrários ao rival (Hameleers, 2016).

A ideologia e o senso de pertencimento a determinado grupo podem criar um estado de cegueira no qual seus membros tendem a desconsiderar informações factuais quando contrariam valores identitários do grupo (Druckman \& Bolsen, 2011). Além disso, a congruência ideológica entre indivíduos e o líder da comunidade a que pertencem pode ter um efeito de ofuscamento, deixando os membros refratários em relação a argumentos e alegações contrários aos valores identitários do grupo.

Com base nessa lógica, seria mais provável que uma alegação contrária às crenças dominantes do grupo seja considerada falsa pelos seus integrantes. Por isso, é provável que as pessoas cheguem a conclusões que confirmem seu viés identitário/ideológico. No entanto, a sustentação de tais conclusões enviesadas requer justificativas minimamente razoáveis (Kunda, 1990). Alguns eventos, entretanto, exercem tamanha influência sobre a vida dos indivíduos que, mesmo membros de grupos fortemente identitários, podem ver suas crenças abaladas. Dito de outra maneira, a identidade/ideologia pode não ser mais suficiente para justificar a aderência do indivíduo ao grupo (Kunda, 1990; Mazar et al., 2008).

É justamente nesses momentos que as identidades se tornam maleáveis e suscetíveis a transformações. Os custos de mudança, portanto, diminuem sensivelmente, e as chances de alguns membros desgarrarem ao considerar outras alternativas identitárias aumentam. 


\section{METODOLOGIA E ESTATÍSTICA DESCRITIVA}

Para investigar a percepção dos brasileiros em relação à política de isolamento social e ao desempenho dos políticos durante a pandemia, realizamos, com o apoio do jornal O Estado de São Paulo, uma pesquisa de opinião entre os dias 28 de março e 4 de abril de 2020. O questionário foi divulgado nas redes sociais, em especial no WhatsApp. Foram coletadas 8.168 respostas. Após a verificação do tempo médio de resposta, fizemos um corte dos questionários com menos de 120 e mais de 960 segundos de duração. Também excluímos da amostra aqueles com número de IP repetidos. A amostra final foi de 7.848 respostas válidas e contou com a participação de respondentes de todos os estados brasileiros, com maior concentração em São Paulo (44\%), Minas Gerais (7\%) e Rio de Janeiro (6\%).

Dos 7.848 respondentes, 50,2\% são do sexo feminino e 49,8, do masculino. Em termos de perfil de renda, $13,5 \%$ ganham até três salários mínimos; $14,6 \%$, até cinco; $22,5 \%$, entre três e cinco; $36,3 \%$ têm renda superior a 10 mil reais; e $12 \%$ preferiram não informar. Quanto ao perfil etário, $5 \%$ têm idade entre 18 e 24 anos; $16 \%$, entre 25 e 34; $20 \%$, entre $35-44$ e $45-55 ; 27 \%$ têm entre 55 e 65 ; e $10 \%$, mais de 65.

Por volta de 32\% dos respondentes se classificaram como grupo de risco da COVID-19, 18\% conhecem alguém que teve a doença no estágio grave e 7\%, alguém que veio a óbito. Em termos de perfil ideológico, $37,1 \%$ se declararam de centro; 30,1\%, como centro-esquerda e esquerda; e $32,8 \%$, como centro-direita e direita. Com relação às consequências econômicas das medidas de isolamento social, $37 \%$ relataram que elas podem acarretar enorme ou total prejuízo financeiro para sua atividade profissional e $32 \%$ acreditam que a quarentena não trará nenhum prejuízo financeiro para sua atividade profissional. ${ }^{3}$

Não utilizamos abordagem probabilística para a seleção da amostra e optamos por não realizar nenhuma pós-estratificação dela, tendo em vista os potenciais riscos de introdução de viés para variáveis não observáveis ou não mensuradas. Há, portanto, limites concernentes à generalização para a população, em especial de resultados descritivos uni ou bivariados, sem a inclusão de variáveis adicionais de controle. Além disso, as principais variáveis demográficas apresentaram bom balanceamento em relação à população, e aquelas com sobre-representação de algum grupo - dos mais ricos na renda e de moradores de São Paulo - não se mostraram preditores relevantes.

Os respondentes foram convidados a participar de uma pesquisa sobre percepção e comportamento em relação ao coronavírus. Após consentimento, todos responderam sobre: (1) a situação em que estavam em relação ao isolamento social; os prejuízos financeiros decorrentes do isolamento para sua atividade; as medidas de isolamento que haviam sido implementadas pelo governo de seus estados e pelo presidente; se conheciam alguém infectado pela COVID-19; (2) quem acreditavam ser a autoridade responsável pelo controle da pandemia no Brasil; (3) como avaliavam as ações implementadas para controle da pandemia pelos governadores e pelo presidente; (4) o grau de concordância com a política de isolamento e por quanto estariam dispostos a ficar isolados; (5) aspectos sócio-demográficos.

As respostas foram apresentadas em múltipla escolha com opção única e escala likert. O intervalo de confiança calculado para todas as médias foi de $95 \%$. Para mensurar a variação da adesão ao

\footnotetext{
${ }^{3}$ Os dados, estatísticas descritivas e todos os scripts com material para replicação encontram-se disponíveis no link: https://dataverse. harvard.edu/dataset.xhtml?persistentId=doi\%3A10.7910\%2FDVN\%2FSUN4KZ15
} 
isolamento entre os respondentes no que concerne ao prejuízo econômico esperado com a pandemia e à exposição de pessoas conhecidas em graus variados aos efeitos do vírus, utilizamos um conjunto de regressões lineares com erros-padrão robustos e regressões logísticas ordinais.

\section{PANDEMIA E IDEOLOGIA}

Para começar a entender o impacto político da pandemia, investigamos de que maneira as preferências ideológicas da população estão relacionadas à avaliação da atuação de Bolsonaro e dos governadores durante a pandemia, em especial quanto ao isolamento social e ao tempo adequado de manutenção dele. Pretendemos, com isso, identificar se há inclinações ideológicas claras e polarizadas no alinhamento às soluções propostas para enfrentamento da pandemia no Brasil ou se a polarização política foi minorada diante dos riscos de contrariar a doença com graus variados de gravidade.

O primeiro ponto que merece destaque é perceber que os respondentes que se auto identificam como de esquerda, centro-esquerda e centro discordam homogeneamente da atuação de Bolsonaro e apoiam os governadores. Por outro lado, respondentes de centro-direita e direita, supostamente o núcleo principal dos eleitores do presidente, divergem consideravelmente sobre as avaliações, ou seja, racharam (Figura 1). Uma parcela maior desses eleitores (56\%) se manteve fiel a ele, mas 40\% discordaram de sua atuação na pandemia, ao passo que 5\% ficaram indiferentes. A divisão dos eleitores de direita e centro-direita ficou mais evidente na avaliação da atuação dos governadores, em que a maioria (60\%) concordou, uma parcela menor discordou (35\%) e 5\% se mostraram indiferentes.

FIGURA 1 AVALIAÇÃO DO PRESIDENTE E DOS GOVERNADORES POR IDEOLOGIA
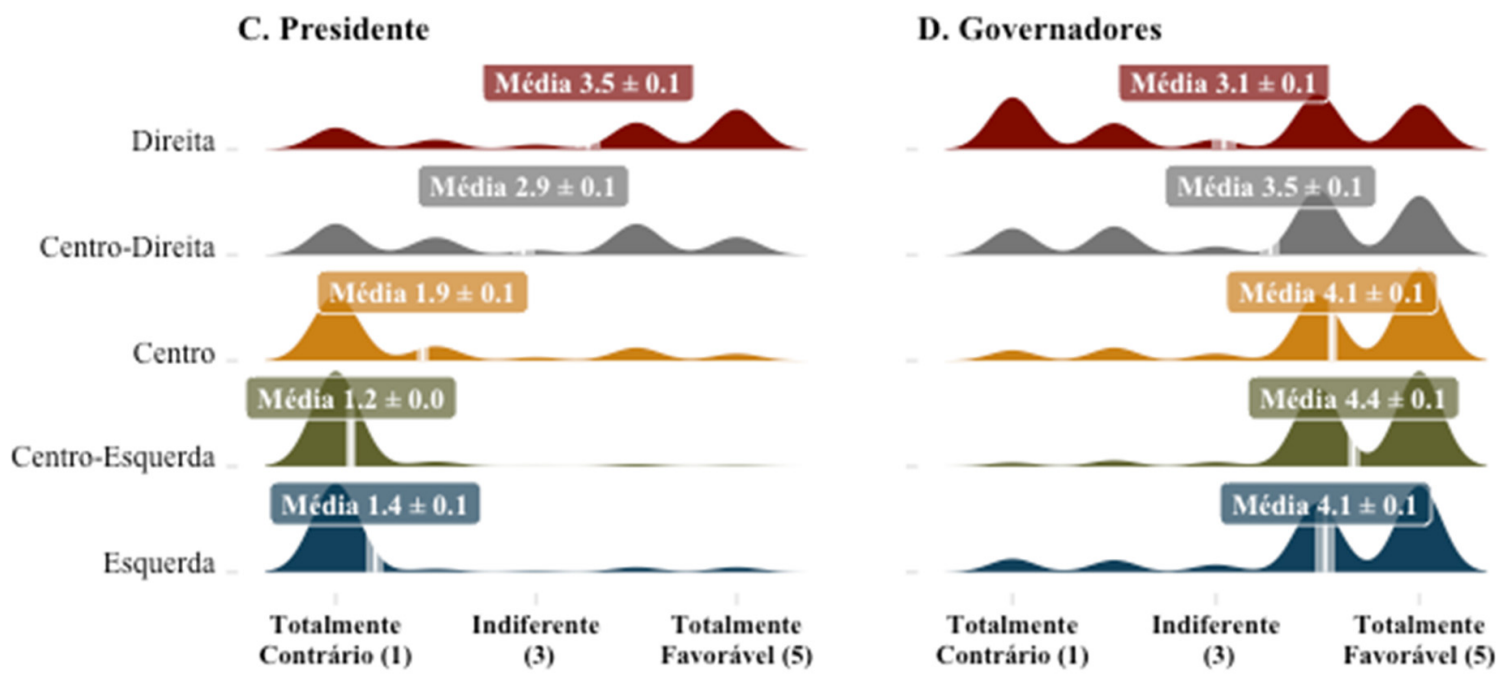

Fonte: Dados da pesquisa. 
Os resultados indicam que a forma diametralmente oposta com que Bolsonaro - minimização da gravidade da doença e destaque aos impactos econômicos negativos que a política de isolamento potencialmente traz - e os governadores - priorização das políticas de isolamento social para diminuir a velocidade de contágio - reagiram à pandemia reconfigurou a polarização política anterior. Um contingente considerável de indivíduos que estariam dando suporte ao presidente migrou em direção ao polo oposto, quebrando o padrão bimodal, característico de cenários polarizados (Bello, 2019). Isso não significa, necessariamente, que as pessoas tenham mudado por completo as lentes através das quais enxergam o mundo ou sua ideologia/identidade política. Contudo, mostra que a pandemia pode ter sido capaz de reposicionar o eixo principal da polarização entre os que se identificam como de direita e centro-direita para além do antagonismo direto com a esquerda.

\section{FIGURA 2 AVALIAÇÕES DO ISOLAMENTO POR IDEOLOGIA}

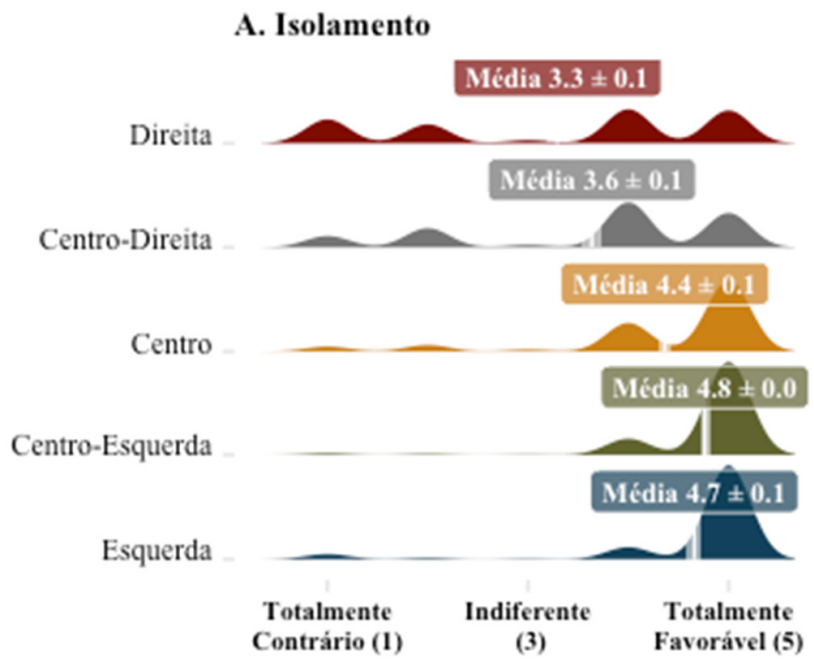

B. Tempo de isolamento

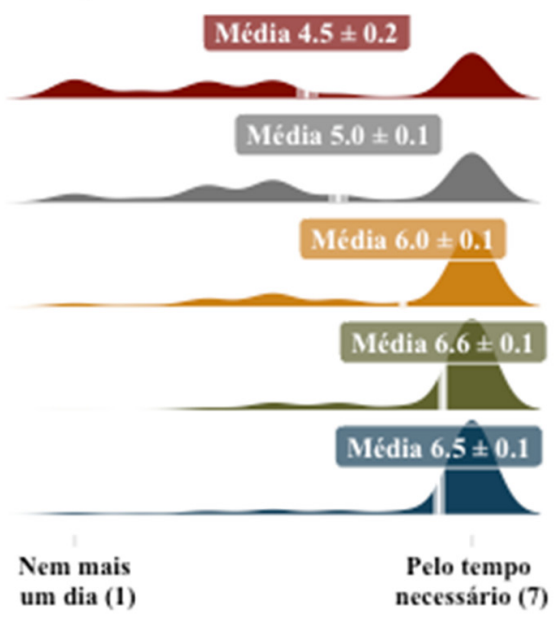

Fonte: Dados da pesquisa.

Esse padrão alternativo de distribuição de preferências fica claro quando cruzamos a posição dos respondentes em relação à política de isolamento social com seus respectivos posicionamentos políticoideológicos (Figura 2). Respondentes de esquerda, centro-esquerda e centro são majoritariamente favoráveis ao isolamento social pelo tempo que for necessário. Entretanto, uma parcela considerável dos eleitores que se autodesignam como de centro-direita e direita também são favoráveis a essa política, contrariando a posição e a recomendação do presidente de relaxar o isolamento social. Pode-se inferir, portanto, que, para além do antagonismo ideológico preexistente, a maioria das pessoas mais à direita não coaduna com a visão do presidente sobre isolamento social. É fundamental entender, pois, os elementos determinantes da mudança do eixo da polarização, que ocorre fundamentalmente entre os eleitores de direita e centro-direita. 


\section{DIREITA DIVIDIDA: ISOLAMENTO SOCIAL É COISA DE RICO?}

Tem ganhado força a interpretação de que a adoção do isolamento social estaria sendo apoiada sobretudo por aqueles com recursos financeiros suficientes para se manter confortavelmente em quarentena. O pressuposto, inclusive reforçado por Bolsonaro, é o de que seria mais viável para o grupo social de maior renda priorizar os cuidados com a saúde e relegar os problemas econômicos gerados pela pandemia a segundo plano. Enquanto isso, famílias em situação econômica mais vulnerável necessitariam voltar logo ao trabalho e apresentariam, assim, maior resistência à manutenção do isolamento social (Jorge, 2020).

\section{FIGURA 3 ISOLAMENTO POR RENDA}

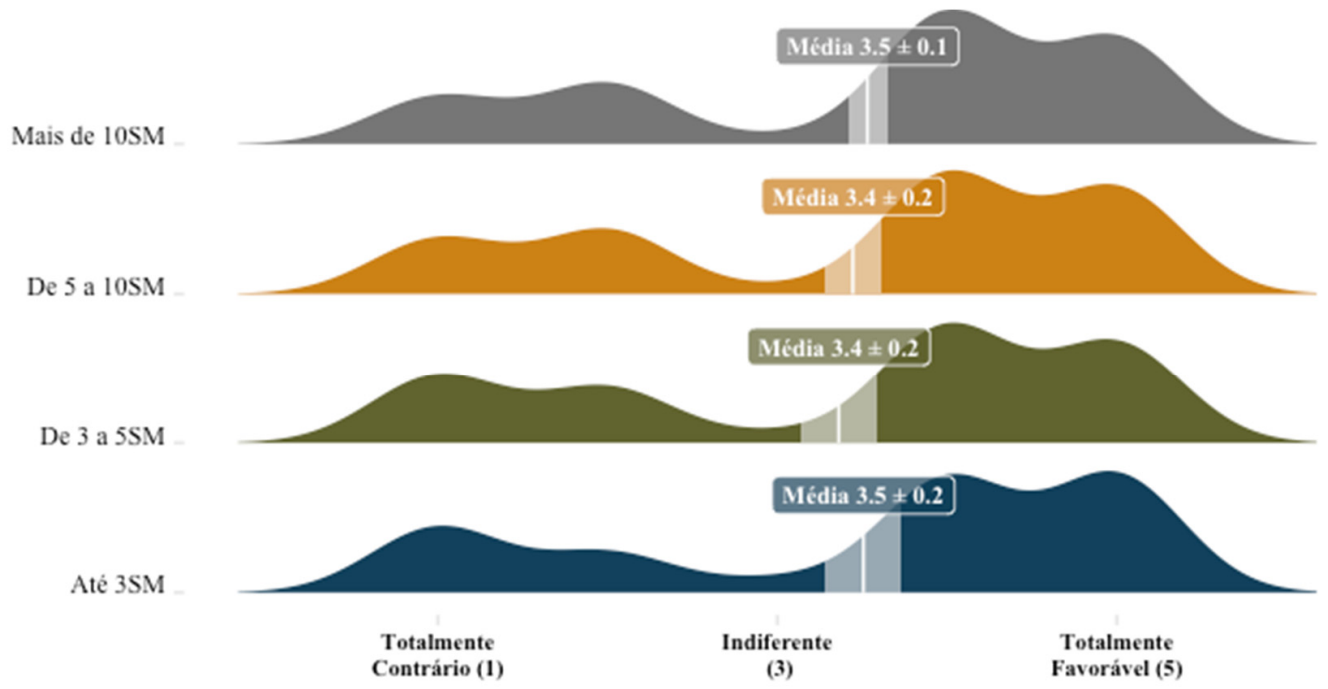

Fonte: Dados da pesquisa.

A fim de verificar tal argumento, testamos se o aparente antagonismo em relação ao isolamento social é de fato baseado nas diferenças de renda. A Figura 3 mostra que, ao contrário da expectativa de que as pessoas com diferentes faixas de renda deveriam exibir distintos padrões de apoio à política de isolamento social, a diferença entre as médias das distintas faixas de renda não é estatisticamente díspar. Ou seja, pelo menos até a semana em que os dados foram coletados, a sociedade não estava cindida pela renda. Os mais pobres e os mais ricos apoiam majoritariamente o isolamento social e se opõem à recomendação do presidente de voltar ao trabalho.

Para as pessoas dos estratos mais altos, a racionalidade fica clara. Como dispõem de meios para proteger sua renda, o isolamento teria custos menores. E quanto aos mais pobres? Como explicar a preferência pelo isolamento? Acreditamos que o argumento de que os mais necessitados seriam mais contrários ao isolamento confunde preferências e decisões. Os dados apontam que, para a maior parte deles, ficar em casa é estritamente preferível a ir trabalhar. Entretanto, como o Executivo federal não sinaliza de forma crível estar empenhado em ofertar suporte econômico, os indivíduos observam tais 
sinalizações e estabelecem um conjunto de crenças a respeito da probabilidade de receberem o apoio. Nesse cenário, as pessoas de baixa renda podem agir estrategicamente e escolher, de modo racional, retomar as atividades profissionais, mas isso não significa uma preferência sincera pelo retorno.

Conforme sugerem Shah, Shah, Mullainathan, e Shafir (2012), a escassez muda a maneira como as pessoas alocam sua atenção, levando-as a se envolver mais profundamente em alguns problemas enquanto negligenciam outros. Assim, a escassez em qualquer de suas formas de manifestações - fome, solidão, falta de tempo e pobreza - capturaria nossa atenção, autocontrole e capacidade de planejamento em longo prazo, direcionando nosso foco ao objeto mais imediato em falta. É o exemplo da situação dos mais pobres na pandemia. Diante da ameaça de morte, eles preferem parar de trabalhar e se manter em isolamento social. No entanto, a falta de recursos para alimentação e moradia vai tirando o foco de atenção no isolamento e o levando para a obtenção de recursos a fim de suprir as necessidades mais imediatas.

\section{O MEDO DA MORTE APROXIMA OS POLOS}

É interessante observar o comportamento de eleitores de direita e centro-direita em relação ao isolamento social levando em consideração a proximidade a pessoas (amigos, parente etc.) que se contaminaram e desenvolveram a COVID-19 com graus variados de gravidade. A Figura 4 mostra claramente que, quanto maior a gravidade da doença em pessoas de seu convívio social, ou, em outros termos, quanto maior o espectro do "medo da morte", mais alto é o apoio à política de isolamento social pelo tempo que for necessário.

\section{FIGURA 4 AVALIAÇÕES DO ISOLAMENTO POR PROXIMIDADE COM PESSOAS INFECTADAS, APENAS} DIREITA E CENTRO-DIREITA
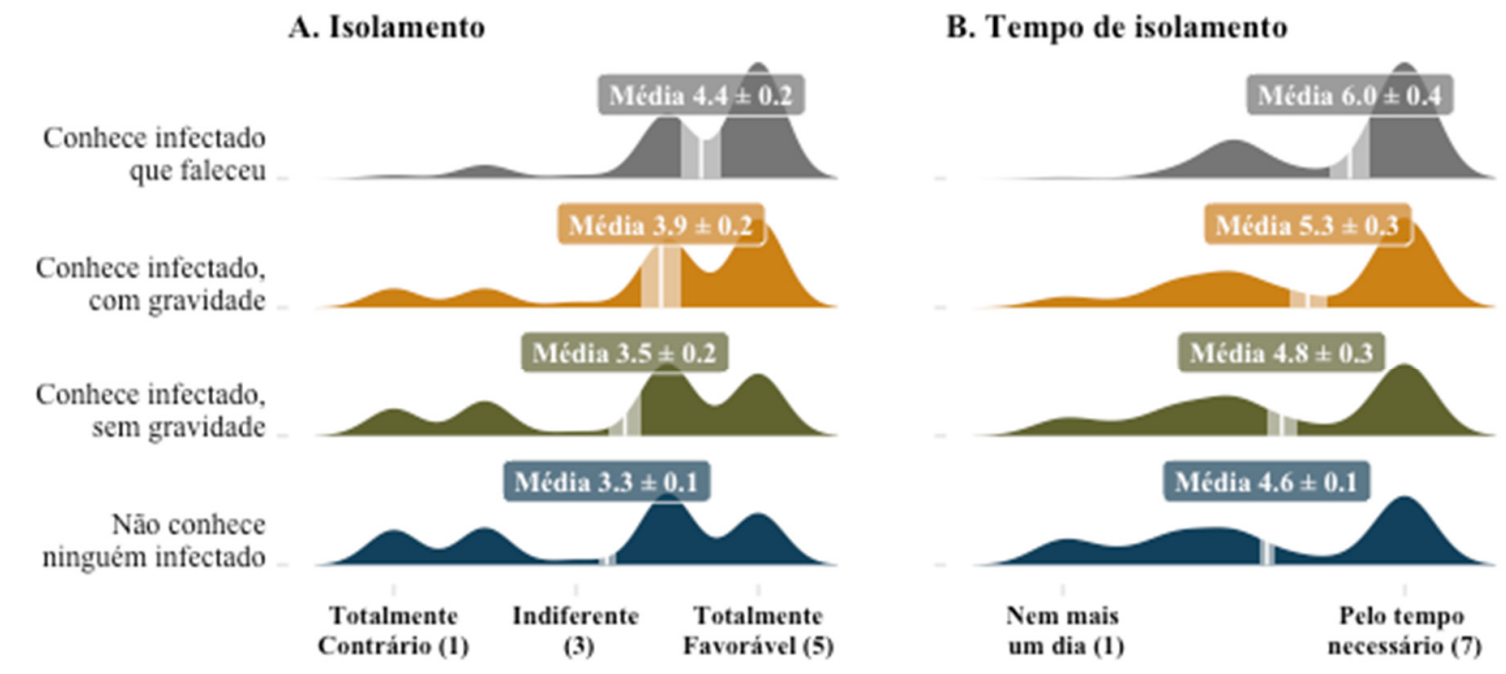

Fonte: Dados da pesquisa. 


\section{FIGURA 5}

\section{AVALIAÇÕES DE POLÍTICOS POR PROXIMIDADE COM PESSOAS INFECTADAS, APENAS DIREITA E CENTRO-DIREITA}
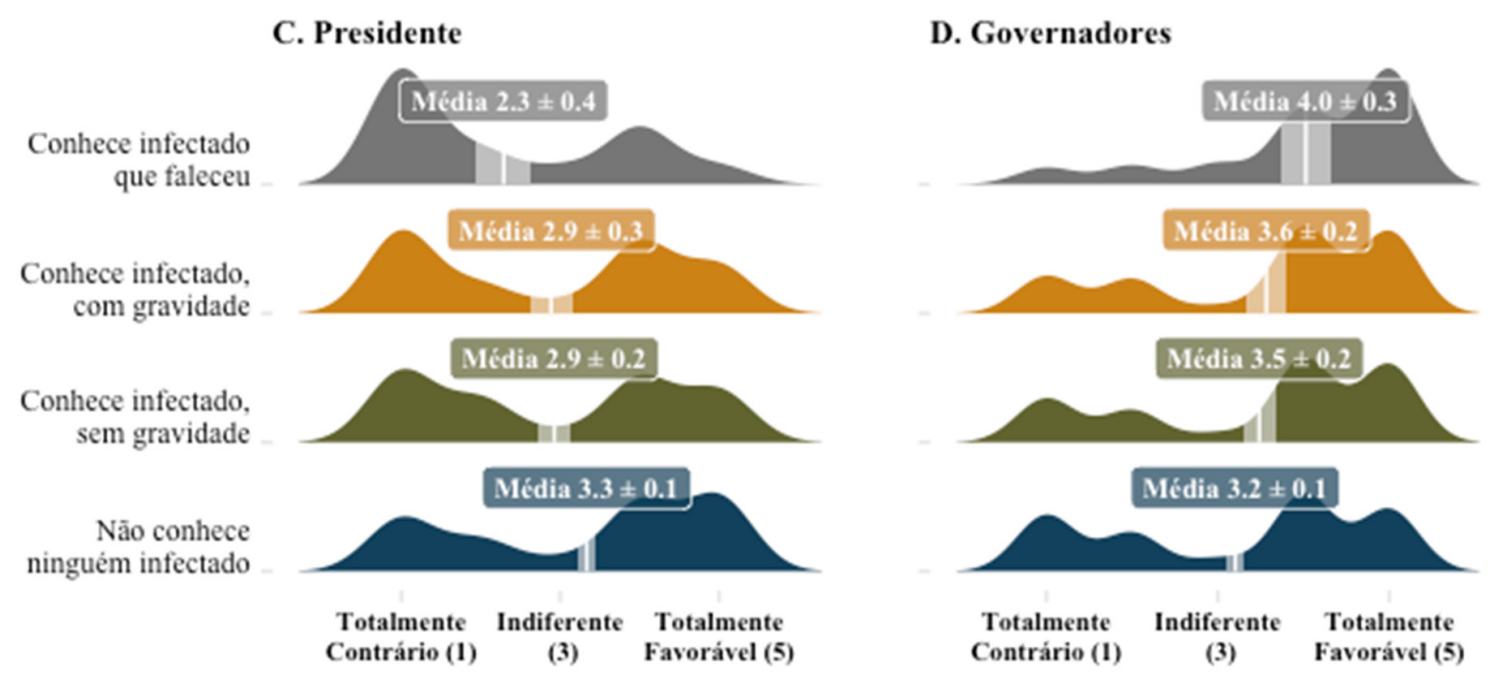

Fonte: Dados da pesquisa.

O efeito da proximidade com o risco de morte associado à COVID-19 também é percebido nas avaliações sobre as ações do presidente e dos governadores. Quanto maior a exposição aos riscos do vírus, menos as pessoas concordam com Bolsonaro e mais com os governadores (Figura 5). Essa é mais uma evidência que reforça a hipótese de que os vínculos identitários entre os eleitores que se autodenominam de direita e centro-direita com Bolsonaro se tornaram mais maleáveis quanto mais próximos esses eleitores se encontram de pessoas que desenvolveram a doença, em especial se vieram a óbito. Em outros termos, diante da fragilização das conexões identitárias, os custos de mudança de posição desses eleitores em relação ao governo diminuíram.

Verificamos anteriormente que a renda não afeta a avaliação sobre o isolamento. Mas o que dizer dos potenciais prejuízos econômicos gerados pela política de isolamento social? A Figura 6 mostra a distribuição dos distintos níveis de prejuízo econômico em função do apoio à recomendação do presidente de flexibilizar o isolamento social correlacionada com o conhecimento de pessoas infectadas pela COVID-19 e seus respectivos graus de gravidade.

Embora, de fato, haja uma relação negativa entre prejuízo econômico esperado e apoio ao isolamento, os níveis de proximidade com a doença fazem diferença nessa relação. Para os que não conhecem pessoas contaminadas, quanto maior o prejuízo, menor o apoio ao isolamento. Porém, entre os que conhecem pessoas que vieram a falecer, essa variação não se verifica. Em outras palavras, a gravidade da contaminação que eventualmente venha a gerar óbito leva as pessoas a minimizar as potenciais perdas econômicas. O medo da morte parece não aproximar apenas polos ideologicamente opostos, mas também diferentes classes sociais e pessoas que estão vivenciando diferentes níveis de prejuízos econômicos em decorrência da política de isolamento social. Os resultados são igualmente consistentes para o apoio ao presidente no sentido oposto ao do apoio ao isolamento e aos governadores. 


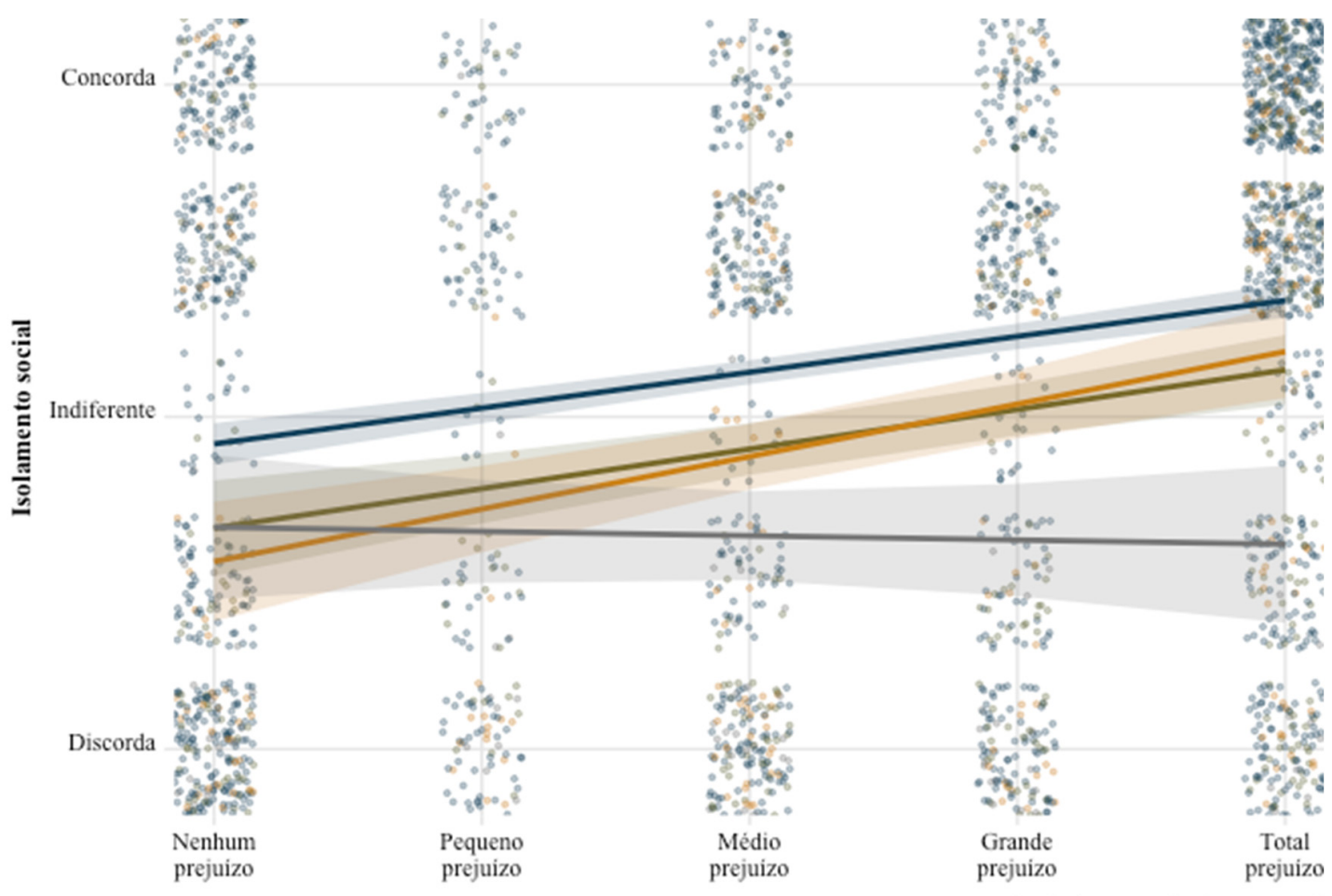

Prejuizo econômico pessoal

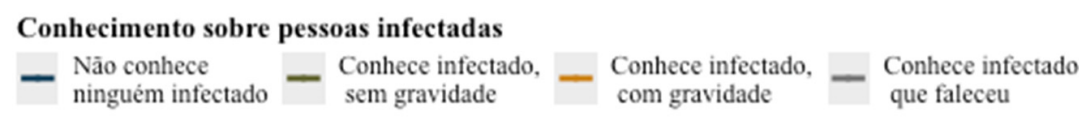

Fonte: Dados da pesquisa.

De forma simplificada, é possível identificar dois grupos de apoiadores de Bolsonaro: os identitários e os pragmáticos. O primeiro grupo é orgânico e apoia o governo porque acredita e aposta no projeto político do presidente. Para que se mantenha coeso, ofertando apoio social básico e seguro, esse grupo necessita ser alimentado constantemente com agendas populistas e polarizadas. Já o segundo grupo apoia o presidente porque acredita que o governo tem capacidade de ofertar o que de fato lhes interessa: políticas econômicas liberais, combate à corrupção e contenção do petismo. ${ }^{4}$

\footnotetext{
${ }^{4}$ Embora nossos dados não nos permitam testar diretamente tal pressuposto, ele encontra um relativo suporte teórico e empírico na literatura sobre guerras culturais (Hunter, 1991; Laclau, 2013; Lakoff, 1996). Especificamente no contexto brasileiro, dados de entrevistas coletadas durante as manifestações de 25 e 31 de março de 2017, por Gallego, Ortellado, e Moretto (2017), indicam que o maior fator de unidade aglutinador desse grupo é o debate anticorrupção e o discurso antipetista entre eleitores autodefinidos como de direita e conservadores. Entre tais eleitores, entretanto, não foi observado um padrão de unidade em torno das pautas morais, o que indica uma organização menos óbvia, mas coerente com a existência de um grupo com valores morais mais progressistas; outro, com um perfil conservador punitivista; e um terceiro, com um perfil conservador religioso. Tais pautas podem ser observadas em pesquisa conduzida pelo Datafolha em outubro de 2018 entre as razões para o voto em Bolsonaro. Desejo de renovação política e antipetismo aglutinaram $55 \%$ das motivações para o voto no candidato, ao passo que razões ligadas a imagem e valores pessoais do candidato conformaram 13\% dos seus eleitores.
} 
A porção pragmática do eleitorado de Bolsonaro já vinha se afastando por uma série de atitudes belicosas do mandatário, que não parecia se propor ao cumprimento do que esse segmento do eleitorado desejava. Enquanto ele radicalizava em assuntos relacionados, por exemplo, a meio ambiente, gênero, minorias, política externa, educação e cultura, seus eleitores de direita estavam dispostos a continuar a apoiá-lo por provavelmente acreditarem que seus riscos individuais de perda no curto prazo eram baixos. Entretanto, quando o presidente se posicionou contra a política de isolamento social, com o objetivo de mitigar suas consequências econômicas, os respondentes interpretaram que tal posicionamento oferecia riscos às suas próprias vidas e a de entes queridos, gerando riscos reais no curto prazo.

Os efeitos visualizados na Figura 6 podem também ser identificados por meio de estimação linear, tendo como variável dependente o apoio à política de isolamento social. Estimamos, apenas para os respondentes que se autodenominaram de direita e centro-direita, diferentes modelos da relação entre exposição à COVID-19 e isolamento. Nossa estimação preferida seguiu a seguinte equação:

$$
\begin{gathered}
\text { isolamento }=\alpha+\beta_{1} \text { covid }+\beta_{2} \text { prejuizo_dummy }+\beta_{3} \text { sexo }+\beta_{4} \text { idade }+\beta_{5} \text { renda }+ \\
\beta_{6}\left(\text { covid }{ }^{*} \text { prejuizo_dummy }\right)+\epsilon
\end{gathered}
$$

As variáveis explicativas dos modelos testados são: 1) proxies de "medo da morte" (variável denominada covid no nosso modelo), mensuradas pela proximidade dos respondentes de pessoas contaminadas pela COVID-19 e seus graus diferentes de gravidade (não conhece, leve, grave e morte); e 2) expectativa de prejuízo econômico com o isolamento social, mensurada por escala likert de 1 a 5 . Como variáveis de controle, incluímos as diferentes faixas de renda, sexo e idade - pessoas acima de 45 anos, pois foi a partir dessa faixa etária que encontramos maior variância nas preferências. Além disso, em alguns dos modelos, incluímos interações entre "medo da morte" e "prejuízo econômico".

Operacionalizamos a variável covid de duas formas distintas: como variável quantitativa (covid num) e como variável qualitativa ordinal (covid), com 4 níveis. Já a variável prejuízo foi operacionalizada como dummy (prejuízo dummy), pelo fato de apenas a categoria de prejuízo total apresentar diferença de média de apoio ao isolamento em relação às demais. A Tabela 1 mostra os resultados das estimações com erros-padrão robustos.

Como pode ser observado na Tabela 1 e na Figura 7, nossas expectativas foram confirmadas. Ou seja, o grau de proximidade de alguém contaminado pela COVID-19 aumenta as chances de apoio ao isolamento social. Fica claro que o grau de apoio ao isolamento social aumenta com a percepção de proximidade ao risco de morte. Em outras palavras, o medo da morte proporcionado pela pandemia é forte o suficiente para fragilizar os laços identitários/ideológicos entre esse grupo de eleitores e o presidente a ponto de esses eleitores contrariarem a orientação de seu líder e apoiar, de forma consistente, o isolamento social. Mantendo as outras variáveis constantes, é possível inferir que quem conhece alguém que morreu pela COVID-19 concorda com a política de isolamento social num nível 19,20\% superior a quem não conhece pessoas contaminadas pelo vírus. Como havíamos mostrado, as diferentes faixas de renda não apresentam impacto estatístico significante no isolamento social. Entretanto, pessoas com expectativas de prejuízo econômico, mais velhas e do sexo masculino tendem a apoiar menos o isolamento social. 


\section{TABELA 1 MODELOS EXPLICATIVOS DA PREFERÊNCIA PELO ISOLAMENTO SOCIAL}

\begin{tabular}{|c|c|c|c|c|}
\hline & Modelo 1 & Modelo 2 & Modelo 3 & Modelo 4 \\
\hline Covid_num & $0.22^{\star \star \star}(0.03)$ & & $0.20^{\star \star \star}(0.03)$ & \\
\hline Prejuizo_dummy & $-0.73^{\star \star \star}(0.07)$ & $-0.81^{\star \star \star}(0.08)$ & $-0.71^{\star \star \star}(0.07)$ & $-0.80^{* * *}(0.08)$ \\
\hline Covid_num: Prejuizo_dummy & $0.14 *(0.06)$ & & $0.16 *(0.06)$ & \\
\hline Covid Leve & & $0.22 *(0.09)$ & & $0.16(0.09)$ \\
\hline Covid Grave & & $0.47^{\star \star \star}(0.12)$ & & $0.42^{\star * \star}(0.12)$ \\
\hline Covid Morte & & $0.87^{\star \star \star}(0.11)$ & & $0.81^{* * *}(0.11)$ \\
\hline Covid Leve: Prejuizo_dummy & & $0.10(0.18)$ & & $0.13(0.18)$ \\
\hline Covid Grave: Prejuizo_dummy & & $0.43^{*}(0.21)$ & & $0.48 *(0.21)$ \\
\hline Covid Morte: Prejuizo_dummy & & $0.52(0.35)$ & & $0.56(0.33)$ \\
\hline Sexo Masculino & & & $-0.53^{\star \star \star}(0.06)$ & $-0.54^{\star \star \star}(0.06)$ \\
\hline Renda De 3 a 5SM & & & $-0.08(0.11)$ & $-0.08(0.11)$ \\
\hline Renda De 5 a 10SM & & & $-0.07(0.10)$ & $-0.06(0.10)$ \\
\hline Renda Mais de 10SM & & & $-0.01(0.09)$ & $0.01(0.09)$ \\
\hline Idade & & & $-0.27^{* \star *}(0.06)$ & $-0.27^{\star * *}(0.06)$ \\
\hline N & 2126 & 2126 & 2126 & 2126 \\
\hline $\mathrm{R} 2$ & 0.09 & 0.09 & 0.13 & 0.14 \\
\hline
\end{tabular}

Todos os preditores contínuos são centralizados na média e redimensionados em 1 desvio padrão. Os erros padrões são heterocedasticamente robustos. ${ }^{* *} \mathrm{p}<0.001 ;{ }^{* *} \mathrm{p}<0.01{ }^{*} \mathrm{p}<0.05$

Fonte: Dados da pesquisa.

\section{FIGURA 7 MODELOS EXPLICATIVOS DA PREFERÊNCIA PELO ISOLAMENTO SOCIAL}

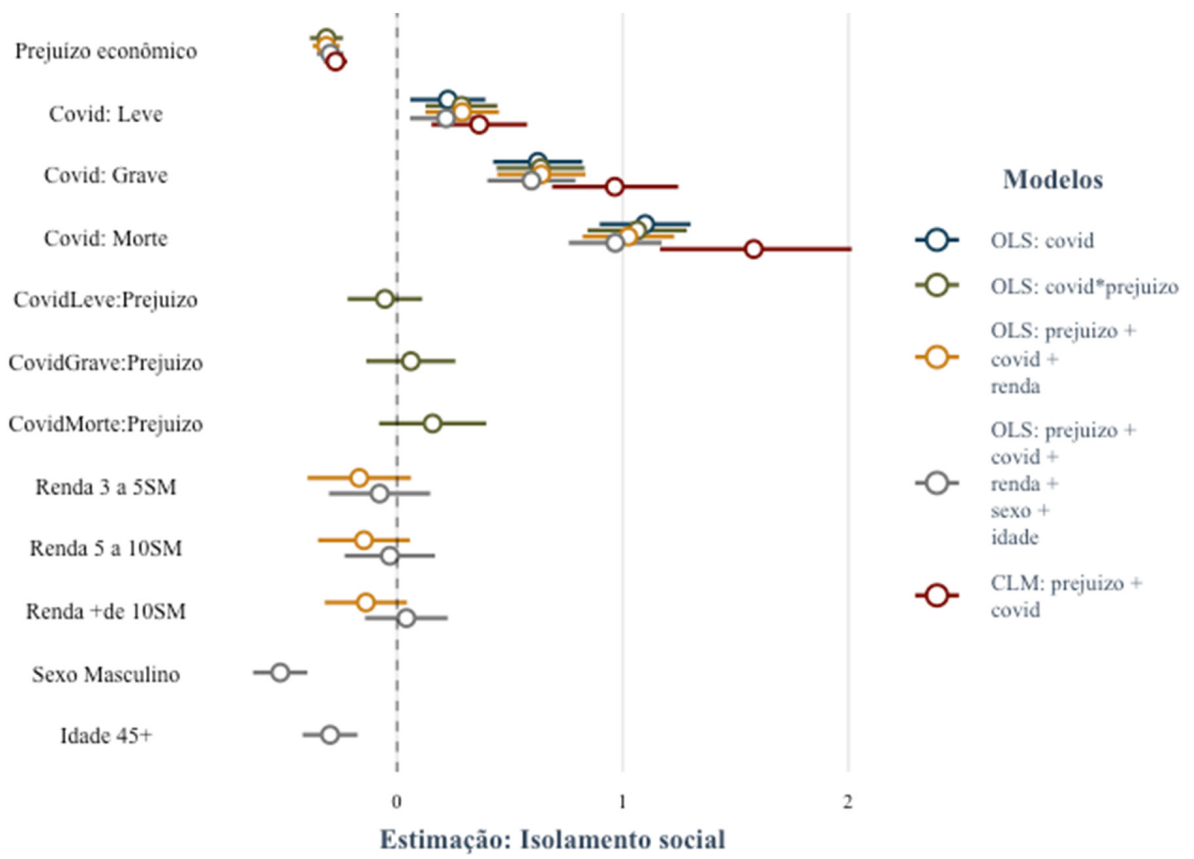

Fonte: Dados da pesquisa. 


\section{CONCLUSÃO}

Crises agudas, como guerras ou pandemias, podem se converter em oportunidades ímpares para governantes que ambicionam deixar um legado para a história, demonstrando capacidade para unir o país em torno de sua liderança e, assim, enfrentar um inimigo comum. Bolsonaro, contudo, parece incapaz de se desvencilhar das amarras por ele mesmo impostas quando decidiu governar na condição de minoria sem um governo de coalizão. Para o presidente, essa foi uma oportunidade perdida, pois foi um dos poucos líderes ao redor do mundo que perderam suporte e popularidade junto aos eleitores (ver Figura 8 no material suplementar) ${ }^{5}$.

Mesmo desgastado por sempre preferir implementar uma campanha perpétua polarizada, o presidente vinha sendo capaz de manter popularidade e apoio político de uma parcela significativa da população. No entanto, ao dar ênfase aos impactos negativos do isolamento social na economia e, ao mesmo tempo, minimizar os riscos de contágio e gravidade da pandemia, até a parcela significativa de eleitores congruentes do ponto de vista ideológico e identitário com seu governo decidiram abandoná-lo.

Bolsonaro não percebeu que o medo da população em perder vidas com o novo coronavírus suplanta os riscos de crise econômica, pois não se deu conta de que as pessoas tendem a descontar o futuro. Ou seja, as preocupações de hoje são sempre maiores do que as que estão por vir. Bolsonaro contrariou os anseios da população, e os sinais de rejeição entre seus supostos seguidores começaram a aparecer. Os panelaços, os inquéritos para investigar a interferência do presidente em órgãos de controle e os vários pedidos de impeachment evidenciam isso.

Nossa pesquisa revelou que, à medida que os indivíduos de nossa amostra tomam conhecimento de vítimas fatais em seu convívio próximo, suas percepções começam a mudar. Eles ficam mais favoráveis ao isolamento e apresentam disposição a praticá-lo por mais tempo, passando a avaliar de forma pior o presidente e melhor os governadores. As conexões identitárias de grupo com o líder se tornam maleáveis e se fragilizam.

É importante reconhecer, entretanto, que nossos estudos ocorreram enquanto a pandemia se desenvolvia, acarretando doença e morte em sua população. Por um lado, fomos capazes de capturar o sentimento de "medo da morte" e sua influência no comportamento político. Por outro, esse sentimento pode estar inflando a reação das pessoas, o que potencialmente seria uma limitação. Além disso, a falta de desenho amostral probabilístico aponta limites para a generalização dos achados.

Mesmo diante dessas limitações, os resultados da pesquisa sugerem que líderes políticos que sinalizam esforço para combater a pandemia podem extrair maiores benefícios do que aqueles mais preocupados em evitar deterioração econômica. A direita se dividiu, porém não por uma questão de renda. A divisão diminui à medida que o risco de morte se torna algo mais palpável. O medo da morte é tão grande que tem relativizado perdas de outras dimensões identitárias.

\footnotetext{
${ }^{5}$ Disponível no link: https://dataverse.harvard.edu/dataset.xhtml?persistentId=doi\%3A10.7910\%2FDVN\%2FSUN4KZ
} 


\section{REFERÊNCIAS}

Ajzenman, N., Cavalcanti, T., \& Da Mata, D. (2020, 22 de abril). More than words: Leaders' speech and risky behavior during a pandemic. SSRN. Recuperado de https://papers.ssrn.com/sol3/papers. cfm?abstract_id=3582908

Bakker, B., Rooduijn, M., \& Schumacher, G. (2016). The Psychological Roots of Populist Voting: Evidence from the United States, the Netherlands and Germany. European Journal of Political Research, 55(2), 1-58.

Bello, A. (2019). Origens, causas e consequências da polarização política. Brasília, DF: Universidade de Brasília.

Bisgaard, M. (2015). Bias will find a way: economic perceptions, attributions of blame, and partisanmotivated reasoning during crisis. The Journal of Politics, 77(3), 849-860.

Bos, L., Schemer, C., Corbu, N., Hameleers, M., Andreadis, I., Schulz, A., ... Fawzi, N. (2020). The effects of populism as a social identity frame on persuasion and mobilisation: evidence from a 15-country experiment. European Journal of Political Research, 59(1), 3-24.

Bolsen, T., Druckman, J. N., \& Cook, F. L. (2014). The influence of partisan motivated reasoning on public opinion. Political Behavior, 36(2), 235-262.

Busby, E. C., Gubler, J. R., \& Hawkins, K. A. (2019). Framing and blame attribution in populist rhetoric. The Journal of Politics, 81(2), 616-630.

Conaghan, C. M. (2008). Ecuador: Correa's plebiscitary presidency. Journal of Democracy, 19(2), 46-60.

Druckman, J. N., \& Bolsen, T. (2011). Framing, motivated reasoning, and opinions about emergent technologies. Journal of Communication, 61(4), 659-688

Hameleers, M., Bos, L., \& Vreese, C. H. (2017). “They did it": The effects of emotionalized blame attribution in populist communication. Communication Research, 44(6), 870-900.

Hawkins, K. A., Kaltwasser, C. R., \& Andreadis, I. (2020, abril). The Activation of Populist Attitudes. Government and Opposition, 55(2), 283-307.
Huckfeldt, R., Levine, J., Morgan, W., \& Sprague, J. (1999). Accessibility and the political utility of partisan and ideological orientations. American Journal of Political Science, 43(3), 888-911.

Huddy, L. (2001). From social to political identity: a critical examination of social identity theory. Political Psychology, 22(1), 127-156.

Hunter, W., \& Power, T. J. (2019). Bolsonaro and Brazil's illiberal backlash. Journal of Democracy, 30(1), 68-82.

Iborra, A. (2005). Beyond identity and ideology: processes of transcendence associated with the experience of conversion. Culture and Psychology, 11(1), 89-100.

Jorge, M. P. (2020). Quarenta é coisa de rico?. Recuperado de https://www.youtube.com/ watch?v=KRcNNWHM2EY

Kernell, S. (2006). Going public: new strategies of presidential leadership. Washington, DC: CQ Press.

Kingstone, P., \& Power, T. J. (2017). Democratic Brazil divided. Pittsburgh, Pennsylvania: University of Pittsburgh Press.

Kovic, M., \& Caspar, C. (2019, 11 de janeiro). Motivated cognition, conspiratorial epistemology, and bullshit: a model of post-factual political discourse politics. Recuperado de https://doi.org/10.31235/ osf.io/bnv2m

Kunda, Z. (1990). The case for motivated reasoning. Psychological Bulletin, 108(3), 480-498.

Leeper, T. J., \& Slothuus, R. (2014). Political parties, motivated reasoning, and public opinion formation. Political Psychology, 35(S1), 129-156.

Martins, P. (2020, 24 de abril). Painel debate falso dilema entre salvar a economia ou a saúde durante a pandemia. ABRASCO. Recuperado de https://www. abrasco.org.br/site/sem-categoria/painel-debatefalso-dilema-entre-salvar-a-economia-ou-a-saudedurante-a-pandemia/47292/

Mazar, N., Amir, O., \& Ariely, D. (2008). The dishonesty of honest people: a theory of self-concept maintenance. Journal of Marketing Research, 155(6), 633-644.

Mudde, C. (2004). The Populist Zeitgeist. Government and Opposition, 39(4), 541-563. 
Mudde, C., \& Kaltwasser, C. R. (2012). Exclusionary vs. Inclusionary Populism: Comparing Contemporary Europe and Latin America. Government and Opposition, 48(2), 147-174.

Mullen, B., Dovidio, J. F., Craig, J., \& Copper, C. (1992). In-group out-group differences in social projection. Journal of Experimental Social Psychology, 28(5), 422-440.

Pereira, F. (2020, 08 de maio). "Não é o isolamento que afeta a economia, é a pandemia”, diz Meirelles. UOL. Recuperado de https://economia.uol. com.br/noticias/redacao/2020/05/08/nao-e-o- isolamento-que-afeta-a-economia-e-a-pandemiadiz-meirelles.htm

Samuels, D., \& Zucco, C. (2018). Partisans, antipartisans and nonpartisans: voting behavior in Brazil. Cambridge, UK: Cambridge University Press.

Shah, A. K., Mullainathan, S., \& Shafir, E. (2012). Some consequences of having too little. Science, 338(6107), 682-685.

Teles, C. D. P. (2009). Linguagem escolare a construção da identidade e consciência racial da criança negra na educação infantil. Anagrama - Revista Científica Interdisciplinar da Graduação, 1(4), 1-14.

\section{Carlos Pereira}

D

https://orcid.org/0000-0002-8978-1493

Ph.D. em Ciência Política; Professor Titular na Escola Brasileira de Administração Pública e de Empresas da Fundação Getulio Vargas (FGV EBAPE). E-mail: carlos.pereira@fgv.br

\section{Amanda Medeiros}

https://orcid.org/0000-0002-0008-3905

Ph.D. em Administração; Professora na Escola Brasileira de Administração Pública e de Empresas da Fundação Getulio Vargas (FGV EBAPE). E-mail: amanda.medeiros@fgv.br

\section{Frederico Bertholini}

https://orcid.org/0000-0002-2480-739X

Ph.D. em Administração; Professor Adjunto no Instituto de Ciência Política da Universidade de Brasília (IPOL/ UNB).E-mail: frederico.bertholini@unb.br 